\title{
STRUCTURAL VENEER BASED COMPOSITE PRODUCTS FROM HARDWOOD THINNING - PART II: TESTING OF HOLLOW UTILITY POLES
}

\author{
Benoit P. Gilbert $^{(1)}$, Ian D. Underhill ${ }^{(1)}$, Henri Bailleres ${ }^{(2)}$, Robbie L. McGavin ${ }^{(2)}$ \\ (1) Griffith School of Engineering, Griffith University, Australia \\ (2) Salisbury Research Centre, Department of Agriculture, Fisheries and Forestry, Queens- \\ land Government, Australia
}

\begin{abstract}
Australian utility pole network is aging and reaching its end of life, with $70 \%$ of the 5 million poles currently in-service nationally installed within the 20 years following the end of World War II. The estimated investment required for the replacement or remedial maintenance of the aging 3.5 millions poles is as high as 1.75 billion dollars. Additionally, an estimated 21,700 high-durability new poles are required each year, representing further investment of 13.5 million dollars per year. Yet, agreements which progressively phase out logging of native forests around Australia have been signed, giving the industry about 25 years to make the transition from Crown native forests to plantations and private forests. As utility poles were traditionally cut from native forest hardwood species, finding solutions to source new poles currently presents a challenge. This paper presents tests on Veneer Based Composite hardwood hollow utility poles manufactured from Gympie messmate (Eucalyptus cloeziana) plantation thinning. Small diameter poles of nominal $115 \mathrm{~mm}$ internal diameter and $15 \mathrm{~mm}$ wall-thickness were manufactured in two half-poles butt jointed together, using 9 veneers per halfpole. The poles were tested in bending and shear, and experimental test results are presented. The mechanical performance of the hollow poles is discussed and compared to hardwood poles cut from mature trees and of similar size. Future research and different options for improving the current concept are proposed in order to provide a more reliable and cost effective technical solution to the current shortage of utility poles.
\end{abstract}

\section{INTRODUCTION}

Utility poles, commonly referred to as "power poles", support the energy network and therefore represent a vital part of the infrastructure in developed countries. Yet, Australia's utility pole network is aging and reaching its end of life with $70 \%$ of the 5 million poles currently in-service nationally installed within the 20 years following the end of World War II. Structural failure of one pole may have severe consequences on local communities and the economy in general.

The estimated investment required for the replacement or remedial maintenance of the aging 3.5 million Australian poles is as high as 1.75 billion dollars. Additionally, an estimated 21,700 high-durability new poles are required each year for ex- 
tending the network and meeting energy demand, representing further investment of 13.5 million dollars per year [1].

Hardwood utility poles have been traditionally used and compared to more intensively manufactured steel, concrete or fibreglass poles, they are still thought to be the most economical and durable solution in terms of life-cycle costs [1]. Yet, due to growing environmental awareness and concerns over the sustainability of native forestry practices, agreements which progressively phase out logging of native forests around Australia have been signed [2]. In South-East Queensland where this project originated, the South East Queensland Forest Agreement (SEQFA) [3] was signed in 1999 and phases out the logging of native forests by 2025, giving the industry 25 years to make the transition from Crown native forests to plantations and private forests. Consequently, the shortage of utility poles is expected to increase dramatically over the next decade while the demand is expected to rise sharply [1]. Finding solutions to eventually replace the aging poles and source new poles currently presents a challenge.

Various alternative solutions to solid timber poles or columns have been proposed in the literature. Adam et. al. [4] analysed the feasibility, design strength and cost of hollow octagonal utility poles manufactured from composite wood flakes panels. The poles were tapered with the wall thickness decreasing with the height. Results indicated that the proposed poles were able to be cost competitive in the market place. Kyoto University has been intensively researching on composite structures ranging from LVL cylinders $[5,6]$ to spirally cylindrical laminated veneer lumbers [7-9]. The latter product is manufactured through a continuous process with veneer tapes winded around a mandrel in clockwise and anticlockwise directions to form an interlocking pattern [7]. Low quality logs were used for the veneer tapes and the distance between butt jointed veneers was found to significantly influence the strength of the product [8]. Piao [10] manufactured 1.2 metres (small-scale) and 6 metres (full-scale) long nonagon hollow poles from knot free pine wood strips. While full-scale poles were not tested to failure, cantilever tests performed on the small-scaled poles showed that shear failure can govern the strength of the poles.

This paper presents tests on Veneer Based Composite (VBC) hardwood hollow utility poles manufactured from Gympie messmate (Eucalyptus cloeziana) plantation thinning, a specie traditionally used in Australia for poles due to its favourable natural durability and strength properties [11]. Six small diameter poles of nominal $115 \mathrm{~mm}$ internal diameter and $15 \mathrm{~mm}$ wall-thickness were manufactured in short lengths of $970 \mathrm{~mm}$. To determine their mechanical characteristics, four poles were tested in pure bending and two poles in predominant shear.

Experimental test results are presented in the paper and a simple failure mechanism model of the poles is also introduced and compared to experimental results. The mechanical performance of the hollow poles is discussed and compared to hardwood poles of similar size cut from native forests. Future research and different options for improving the current concept are proposed in order to provide a more reliable and cost effective technical solution to the current shortage of utility poles. 
As mentioned in the companion paper [12], research is currently underway on how best to connect short lengths of VBC products to form useable beams and columns. The determination of the mechanical characteristics (stiffness and strength) of these connections is outside the scope of the present paper.

\section{EXPERIMENTAL STUDY}

\subsection{General}

Twelve half-poles were manufactured around a $115 \mathrm{~mm}$ diameter steel mandrel in lengths of $970 \mathrm{~mm}$ using the process detailed in the companion paper [12]. Each half-pole was manufactured at ambient temperature and moisture content using resorcinol formaldehyde structural adhesive from 9 veneers of $1.7 \mathrm{~mm}$ nominal thickness, i.e. forming a nominal wall-thickness of $15 \mathrm{~mm}$. Veneers were delivered in sheets of $1.2 \mathrm{~m} \times 1.2 \mathrm{~m}$ and different sheets were randomly selected for each layer constituting a half-pole. Two half-poles were butt jointed together using structural epoxy resin to form a complete section, as shown in Figure 1.

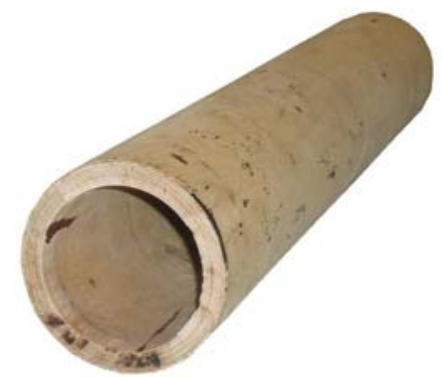

Figure 1: Example of a manufactured pole

Additionally, to determine the mechanical properties of each half-pole, flat panels were also manufactured using the same veneer sheets as each half-pole, glued in the exact same order.

Before testing, hollow poles and flat panels were left at $20^{\circ} \mathrm{C}$ and $65 \%$ relative humidity until they reached equilibrium at an average measured oven dry moisture content of $14.3 \%$.

\subsection{Bending tests}

\subsubsection{Test set-up}

Four timber poles were tested in a $500 \mathrm{kN}$ MTS universal testing machine in four point bending to determine their bending stiffness and maximum bending capacity. The tests were run in displacement control and reached failure in about 7 mins (Tests 1 and 2) and 4.5 mins (Tests 3 and 4).

Each end of the poles was rigidly connected to a steel tube of length $L_{1}=1,045$ $\mathrm{mm}$, as shown in Figure 2, to form beams of length $L=2,930 \mathrm{~mm}$, i.e. about 20 
times the external diameter of the tested poles. At the connection with the steel tubes, polyester resin (pre-filled with $40 \%$ sawdust) was poured (see insert in Figure 2) (i) inside the poles to avoid ovalisation (local crushing) of the timber section and (ii) on the outside of the poles to match the inside diameter of the steel tube and ensure a tight fit between the two elements. Additionally, the steel tubes were slotted over $300 \mathrm{~mm}$ at their top and bottom, and a bolted device was used to sandwich the timber poles in the steel tubes, creating friction between the two elements. The butt joints between two half-poles lied in the horizontal plane.

Three Linear Variable Displacement Transducers (LVDT) recorded the displacement of the timber poles at their centrelines (LVDT 1) and at a distance $d=260$ $\mathrm{mm}$ from their centrelines (LVDTs 2 and 3), as shown in Figure 2.

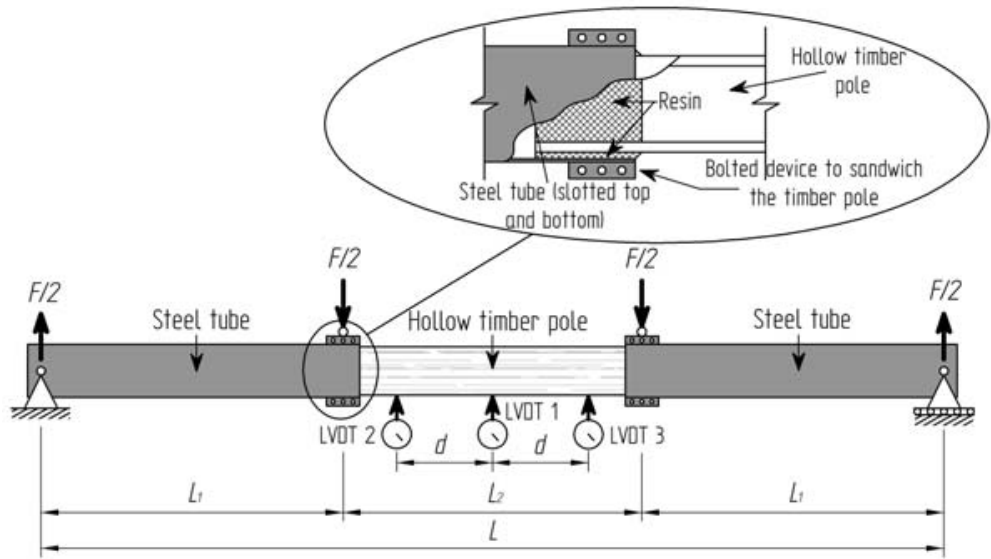

Figure 2: Four point bending test set-up

\subsubsection{Test results}

Table 1 gives the moment capacity $M_{b}$ of the poles calculated as,

$$
M_{b}=\frac{F_{\max }}{2} L_{1}
$$

where $F_{\max }$ is the total maximum applied load and $L_{l}$ is the distance from the supports to the points of application of the loads, as shown in Figure 2.

The bending stiffness $E_{p} I_{p}$ of the poles is also given in Table 1 and calculated by performing a linear regression on the linear part of the load-displacement curve,

$$
F=\frac{4 E_{p} I_{p}}{L_{1} d^{2}}\left(\delta_{1}-\frac{\delta_{2}+\delta_{3}}{2}\right)
$$

where $L$ is the distance between supports, $d$ the distance between transducers and $\delta_{i}$ is the recorded displacement of LVDT number $i$. The second moment of area $I_{p}$ of the poles, calculated from measured external diameter and wall-thickness, is also given in Table 1 for information.

In Test 2, failure developed at the compression side of the sample with the pole opening up, as shown in Figure 3. In Tests 1, 3 and 4, shear failure occurred at the 
connection with the steel tubes and therefore the moment capacities $M_{b}$ given in Table 1 represent lower bound values of the actual capacity of the tested samples. Despite successive improvements of the test rig, the latter failure mode was not eliminated and the rig will need to be redesigned in the future. Yet, the moment capacities for Tests 1,3 and 4 are within $2 \%$ of the capacities calculated using the simple failure mechanism model detailed in Section 3, suggesting that shear failure in the steel/timber connection occurred at a similar applied moment than the failure mode introduced in Section 3.

Table 1: Bending test results

\begin{tabular}{c|ccc}
\hline Test/Pole & $M_{b}(\mathrm{kN} . \mathrm{mm})$ & $E_{p} I_{p}\left(\mathrm{kN} . \mathrm{mm}^{2}\right)$ & $I_{p}\left(\mathrm{~mm}^{4}\right)$ \\
\hline 1 & 17,450 & $2.67 \times 10^{8}$ & $1.40 \times 10^{7}$ \\
2 & 17,250 & $2.30 \times 10^{8}$ & $1.39 \times 10^{7}$ \\
3 & 18,380 & $2.28 \times 10^{8}$ & $1.47 \times 10^{7}$ \\
4 & 14,420 & $1.60 \times 10^{8}$ & $1.43 \times 10^{7}$ \\
\hline
\end{tabular}

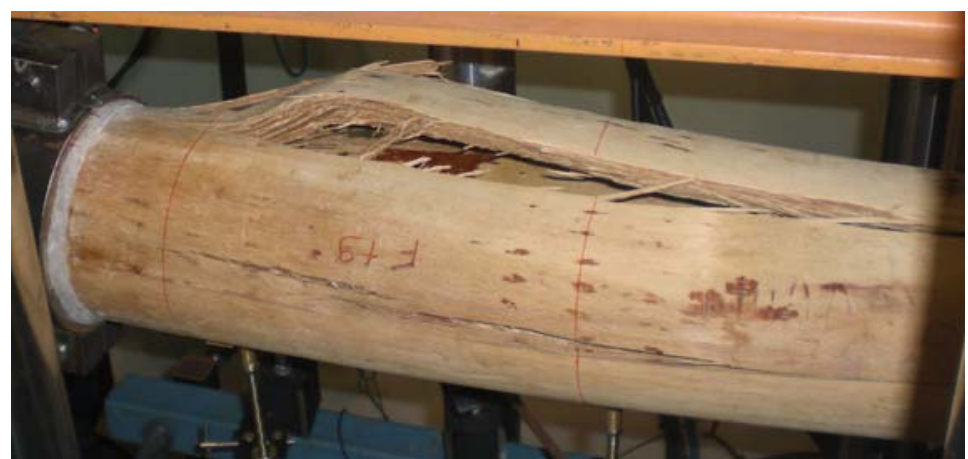

Figure 3: Failure mode for Test 2

\subsection{Shear tests}

\subsubsection{Test set-up}

Two timber poles were tested in a $500 \mathrm{kN}$ MTS universal testing machine in three point bending to determine their shear capacity. The tests were run in displacement control and reached failure in about 11 mins (Test 1) and 3.5 mins (Test 2).

The poles were simply supported, with a distance between supports of $L=820$ $\mathrm{mm}$ in Test 1 and $730 \mathrm{~mm}$ in Test 2, and the load was applied at the centreline of the poles, as shown in Figure 4. To avoid local crushing, polyester resin (pre-filled with $40 \%$ sawdust) was poured inside the timber poles at the point of application of the load and at the supports. The butt joints between two half-poles lied in the horizontal plane in Test 1 and vertical plane in Test 2.

Three Linear Variable Displacement Transducers (LVDT) recorded the displacement of the timber poles at their centrelines (LVDT 1) and at a distance $d$ from their centrelines (LVDTs 2 and 3), as shown in Figure 4, with $d=410 \mathrm{~mm}$ in Test 1 (i.e. at the supports) and $260 \mathrm{~mm}$ in Test 2. 


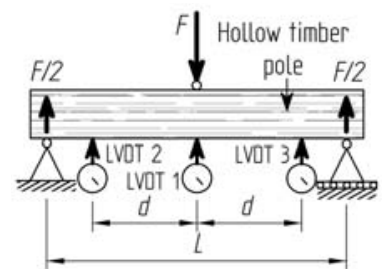

Figure 4: Three point bending test set-up

\subsubsection{Test results}

The shear capacities $V_{s}$ of the poles calculated as,

$$
V_{s}=\frac{F_{\max }}{2}
$$

where $F_{\max }$ is the maximum applied load, was found to be equal to $34.7 \mathrm{kN}$ for Test 1 and $40.7 \mathrm{kN}$ for Test 2 . This corresponds to shear strengths $\tau_{s}$, calculated using the following approximate equation for tubes,

$$
\tau_{s}=2 \frac{V_{s}}{A}
$$

where $A$ is the measured cross-sectional area of the poles, of $10.1 \mathrm{MPa}$ for Test 1 and 12.4 MPa for Test 2 .

Measured combined bending and shear stiffness can be found in [13].

\subsection{Material testing}

For the four poles in bending (see Section 2.2), coupon (dog bone) samples, with $50 \mathrm{~mm}$ wide $\times 225 \mathrm{~mm}$ long necks, were cut from the flat panels of the half-pole undergoing tension, while the flat panels of the half-pole undergoing compression were cut in two, reglued to form $30 \mathrm{~mm}$ nominal thick panels and further cut into nominal $85 \mathrm{~mm}$ wide $\times 180 \mathrm{~mm}$ long samples. The former samples were tested in tension and the latter samples in compression following the method proposed in the Australian and New-Zealand Standard AS/NZS 4357.2 [14] in a $500 \mathrm{kN}$ MTS universal testing machine, at the same strain rate as their associated poles. Three samples were tested per half-pole.

The Modulus of Rupture (MOR) in tension $\sigma_{f, t e n s}$ and in compression $\sigma_{f, \text { comp }}$ of the tension and compression samples, respectively, were calculated as,

$$
\sigma_{f, \text { tens }}=\frac{P_{\max }}{b d} \text { and } \sigma_{f, \text { comp }}=\frac{P_{\max }}{b d}
$$

where $P_{\max }$ is the maximum tensile or compressive applied load, and $b$ and $d$ are the measured width and depth of the tension or compression samples, respectively. Table 2 gives the average measured MOR for all poles tested in bending. Additionally, to accurately measure the Modulus of Elasticity (MOE) $E$ of the material and avoid measuring out-of-straightness deformations as well as tension or compression deformations, two extensometers were positioned on opposite 
sides of the tension or compression samples. The MOE of each sample was calculated as the average of the MOE given by the two extensometers, measured by performing a linear regression on the linear part of the stress-strain curve. Table 2 gives the average measured $\mathrm{MOE}$ for the four poles tested in bending.

Table 2: Average MOE and MOR for the four poles tested in bending

\begin{tabular}{|c|c|c|c|c|c|c|c|c|}
\hline \multirow[b]{2}{*}{ Test/Pole } & \multicolumn{4}{|c|}{ Half pole in compression } & \multicolumn{4}{|c|}{ Half pole in tension } \\
\hline & $\begin{array}{l}\sigma_{f, \text { comp }} \\
(\mathrm{MPa})\end{array}$ & $\mathrm{CoV}$ & $\begin{array}{c}E \\
(\mathrm{GPa})\end{array}$ & $\mathrm{CoV}$ & $\begin{array}{c}\sigma_{f, \text { tens }} \\
(\mathrm{MPa})\end{array}$ & $\mathrm{CoV}$ & $\begin{array}{c}E \\
(\mathrm{GPa})\end{array}$ & $\mathrm{CoV}$ \\
\hline 1 & 61.3 & 0.068 & 17.9 & 0.071 & 94.7 & 0.038 & 19.2 & 0.034 \\
\hline 2 & 60.8 & 0.019 & 17.9 & 0.048 & 90.3 & 0.049 & 19.1 & 0.044 \\
\hline 3 & 66.2 & 0.020 & 20.9 & 0.017 & 84.9 & 0.050 & 18.8 & 0.025 \\
\hline 4 & 55.9 & 0.030 & 15.8 & 0.030 & 68.5 & 0.066 & 15.7 & 0.007 \\
\hline
\end{tabular}

Tested material properties for the two poles tested in predominant shear can be found in [13].

\section{SIMPLE FAILURE MECHANICAL MODEL IN BENDING}

This section develops a simple failure mechanism model of the timber poles in bending, based on perfect elastic-plastic (as encountered in Section 2.4) and brittle behaviours of the material in compression and tension, respectively. Typically, timber fails in tension at a higher stress than in compression, as shown in Table 2, and therefore, plastic deformation would occur in the compressive side of the poles before reaching the failure tensile stress $\sigma_{f, \text { tens }}$ in the tension side. In reference to Figure 5, the stress $\sigma(x)$ at a distance $x$ from the centreline of the pole is given as,

$$
\sigma(x)=\left\{\begin{array}{l}
\sigma_{f, c o m p} \text { if } x \geq 0 \text { and } \varepsilon(x) \geq \varepsilon_{\text {plastic }} \\
E_{\text {top }} \varepsilon(x) \text { if } x \geq 0 \text { and } \varepsilon(x) \leq \varepsilon_{\text {plastic }} \\
E_{\text {bot }} \varepsilon(x) \text { if } x \leq 0
\end{array}\right.
$$

where $E_{t o p}$ and $E_{b o t}$ are the MOE of the top half-pole in compression and bottom half-pole in tension, respectively, $\varepsilon(x)$ is the strain at a distance $x$ from the centreline of the pole and $\varepsilon_{\text {plastic }}$ is the value of the compressive strain where plastification occurs, given as,

$$
\varepsilon_{\text {plastic }}=\frac{\sigma_{f, c o m p}}{E_{\text {top }}}
$$

The tensile and compressive forces $F_{\text {tens }}$ and $F_{\text {comp }}$ in the pole, respectively, are calculated as,

$$
F_{\text {tens }}=\iint_{x=-\frac{D}{2}}^{x=d} \sigma(x) d A(x) \text { and } F_{\text {comp }}=\iint_{x=d}^{x=\frac{D}{2}} \sigma(x) d A(x)
$$

where $D$ is the external diameter of the pole, $d$ is the shift in the neutral axis due to the plastification in the compressive side of the pole and $d A(x)$ is the differential area, as shown in Figure 5. The bending moment $M$ in the pole is then given as, 


$$
M=F_{\text {comp }} e=F_{\text {tens }} e
$$

where $e$ is the lever arm between the resultants of the tensile and compressive forces, as shown in Figure 5.

In sawn timber structures, bending failure is typically triggered by brittle failure in the tensile side of the structure. A similar typical failure mode is hypothetically assumed for hollow timber structures, and specifically that failure occurs when the tensile stress reaches $\sigma_{f \text { tens }}$ at $x=-D / 2+t_{b o t} / 2$ (i.e. at an average stress in the bottom wall of the pole of $\sigma_{f, t e n s}$ ), as shown in Figure 5 , the moment capacity $M_{b}$ of the pole is then calculated by solving $F_{\text {tens }}=F_{\text {comp }}$ in Eq. (8) and finding the shift in neutral axis $d$ and lever arm $e$.

Table 3 gives the moment capacity $M_{b}$ numerically calculated for each tested pole in Section 2.2 by using the calculated MOE and MOR given in Table 2, and measured external diameter $D$ and wall-thickness of the top and bottom half-poles $t_{\text {top }}$ and $t_{\text {bot }}$, respectively. Comparison with actual moment capacities, given in Table 1 , is also provided in Table 3 .

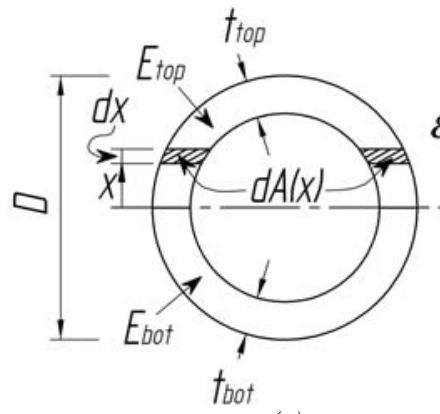

(a)

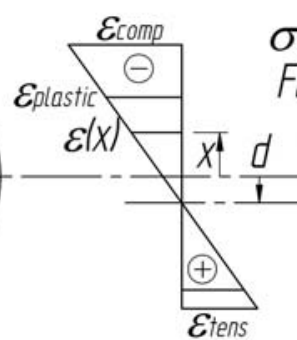

(b)

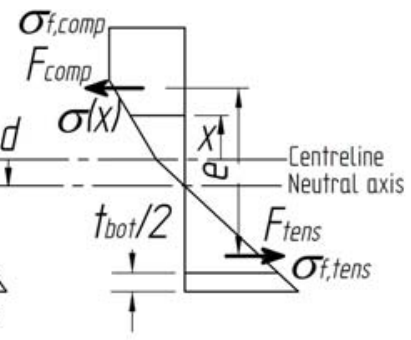

(c)

Figure 5: Simple failure mechanism in bending, (a) pole cross-section, (b) strain distribution and (c) stress distribution

Table 3: Simple failure mechanism model results

\begin{tabular}{c|cc}
\hline Test/Pole & $M_{b}$ (model) $(\mathrm{kN} . \mathrm{mm})$ & $M_{b}$ (model) $/ M_{b}$ (test) \\
\hline 1 & 17,630 & 0.99 \\
2 & 17,110 & 0.98 \\
3 & 17,990 & 1.02 \\
4 & 14,760 & .901 \\
\hline
\end{tabular}

Results in Table 3 show that the simple failure mechanism model provides a good approximation of the actual moment capacity of the poles. Furthermore, Table 3 suggests that the observed failure modes in Section 2.2.2 result in similar or slightly lower moment capacity $M_{b}$ than the typical bending failure mode for timber structures considered in the present failure mechanism model. 


\section{DISCUSION}

\subsection{Comparison with existing poles}

The Australian/New Zealand standard AS/NZS 4676 [15] classifies timber utility poles in seven strength groups ranging from bending characteristic strength $f_{b}^{\prime}$ of $100 \mathrm{MPa}$ (Strength group S1) to $25 \mathrm{MPa}$ (Strength group S7), and shear characteristic strength $f_{s}^{\prime}$ of 7.2 $\mathrm{MPa}$ (Strength group S1) to $2.5 \mathrm{MPa}$ (Strength group S7). Considering a duration of peak load of less than 5 seconds, a full length preservative treated, unshaved and not steamed solid pole (see [15] for more details), the moment capacity $M_{b}$ of the pole is given as [15],

$$
M_{b}=f^{\prime}{ }_{b} Z
$$

where $Z$ is the section modulus, and the shear capacity $V_{s}$ as [15],

$$
V_{s}=f^{\prime}{ }_{s} A_{s}
$$

where $A_{s}$ is the shear plane area, equal to $3 / 4$ the cross-sectional area for solid round cross-sections.

Therefore, a $145 \mathrm{~mm}$ external diameter solid utility pole cut from mature trees would have a minimum moment capacity of 29,930 kN.mm in Strength group S1, i.e. 1.6 times more than the maximum capacity found in Table 1 (pole number 3 ), and of 7,483 kN.mm in Strength group S7, i.e. 1.9 less than the minimum capacity found in Table 1 (pole number 4). Specifically in terms of moment capacity, pole number 4 in Table 1 would be classified in Strength group S5, while poles numbers 1 to 3 in Table 1 would be classified in Strength group S4. While the investigated poles fall in intermediate strength groups, they are 2.7 times lighter than solid utility poles of the same overall dimension. Furthermore, the manufacturing process would allow customising the diameter and wall-thickness of the hollow pole to meet any desired design capacity. For instance, using the simple failure mechanism model developed in Section 3, a hollow pole of external diameter $D=$ $175 \mathrm{~mm}$, wall thickness $t=25 \mathrm{~mm}$, MOE $E=18 \mathrm{GPa}$, MORs $\sigma_{f, \text { tens }}=70 \mathrm{MPa}$ and $\sigma_{f, \text { comp }}=55 \mathrm{MPa}$ (similar to tested pole number 4 in Section 2.2) would have a moment capacity of $30,050 \mathrm{kN} . \mathrm{mm}$, i.e. similar capacity and 1.4 times lighter than a $145 \mathrm{~mm}$ diameter solid utility pole in Strength group S1.

Additionally, the investigated poles in Section 2.3 would be classified in Strength groups S6 and S7 in terms of shear capacity. Yet, the dimensions of the pole can also be customised to meet any desired shear capacity $V_{s}$. Considering a shear strength $\tau_{s}$ of $10 \mathrm{MPa}$ (as experimentally found in Section 2.3.2) and Eq. (4), the $175 \mathrm{~mm} \times 25 \mathrm{~mm}$ hollow pole in the previous paragraph would have a similar shear capacity than a $145 \mathrm{~mm}$ solid pole in Strength group S4.

\subsection{Future research}

As seen in Section 4.1 and previous studies [10], the shear capacity of hollow poles can govern the design. Immediate future studies will investigate crosslaminating the veneers at angles of $+/-10^{\circ}$ with the pole longitudinal axis (similar to [8]). This configuration should significantly increase the shear capacity of the 
poles while marginally reducing their moment capacity. Additional studies would also include (i) investigating the influence of the high proportion of natural defects in waste thinning on the strength and variability in the mechanical properties of thinning composite products, (ii) understanding the behaviour and particular failure modes of the hollow poles and (iii) ultimately establishing probability-based limit state design criteria for the proposed sections, resulting in immediate benefit to the community.

\section{CONCLUSION}

This paper presented bending, shear and material tests on VBC hardwood hollow utility poles manufactured from plantation thinning. A simple failure mechanism model in bending was able to reproduce the actual failure capacities. Results show that the poles are able to compete with hardwood solid poles cut from mature trees and of similar size. While the shear capacity of the hollow poles needs to be enhanced, poles can be custom-built to meet any desired bending and shear capacities. Future research and different options for improving the current concept are also proposed, including cross-laminating veneers at angles of $+/-10^{\circ}$.

\section{ACKNOWLEDGMENT}

The authors would like to thank the Department of Agriculture, Fisheries and Forestry, Australian Government and Forest and Wood Products Australia for their financial support through the "2012, Science and innovation award for young people in agriculture, fisheries and forestry", Forestry category.

\section{REFERENCES}

[1] L. Francis, J. Norton, Australian timber pole resources for energy networks, A review, Department of Primary Industry and Fisheries, Queensland Government, Brisbane, Australia, 2006.

[2] Australian Government, Department of Agriculture Fisheries and Forestry, Regional Forest Agreements, http://www.daff.gov.au/forestry/policies/rfa, Accessed on 01/06/2013.

[3] Queensland Government, Department of Environment and Resource Management, South East Queensland Forests Agreement (SEQFA), http://www.timberqueensland.com.au/Growing/SEQFA.aspx, Accessed on 01/06/2013.

[4] R.D. Adams, G.P. Krueger, A.E. Lund, D.D. Nicholas, "Development of utility poles from composite wood material", Proceedings of the 7th IEEE/PES Transmission and Distribution Conference and Exposition (Ed.: IEEE Service center), Atlanta, U.S.A., 37-40, 1979.

[5] H. Sasaki, S. Kawai "Recent research and development work on wood composites in Japan", Wood Science and Technology, 28, 241-248, 1994. 
[6] Y. Hara, S. Kawai, H. Sasaki "Manufacture and mechanical properties of cylindrical laminated veneer lumber", Japan Wood Research Society, 81, 28-30, 1994.

[7] T. Hata, K. Umemura, H. Yamauchi, A. Nakayama, S. Kawai, H. Sasaki "Design and pilot production of a spiral-winder for the manufacture of cylindrical laminated veneer lumber", Journal of Wood Science, 47, 115-123, 2001.

[8] P. Berard, P. Yang, H. Yamauchi, K. Umemura, S. Kawai "Modeling of a cylindrical laminated veneer lumber I: mechanical properties of hinoki (Chamaecyparis obtusa)and the reliability of a nonlinear finite elements model of a four-point bending test", Journal of Wood Science, 1-7, 2011.

[9] P. Berard, P. Yang, H. Yamauchi, K. Umemura, S. Kawai "Modeling of a cylindrical laminated veneer lumber II: a nonlinear finite element model to improve the quality of the butt joint", Journal of Wood Science, 1-7, 2011.

[10] C. Piao, Wood laminated composite poles, $\mathrm{PhD}$ Thesis, School of renewable natural ressources, Louisiana State University, Louisiana, U.S.A., 2003.

[11] K.R. Bottle, Wood in Australia, Types, properties and uses, (McGraw-Hill), Sydney, Australia, 1983.

[12] I.D. Underhill, B.P. Gilbert, H. Bailleres, R.L. McGavin, D. Patterson, "Structural Veneer Based Composite products from hardwood thinning - Part I: Background and manufacturing", Proceedings of the RILEM Conference "Materials and Joints in Timber Structures - Recent Advancement of Technology", Stuttgart, Germany, 2013.

[13] B.P. Gilbert, I.D. Underhill, A. El Hanandeh, H. Bailleres, R.L. McGavin "Structural Veneer Based Composite products from hardwood thinning - Part III: Testing of hollow utility poles", ASCE Journal of Material in Civil Engineering (In preparation).

[14] AS/NZS 4357.2, Structural laminated veneer lumber, Part 2: Determination of structural properties - Test methods, Standards Australia, Sydney, Australia, 2006.

[15] AS/NZS 4676, Structural design requirements for utility services poles, Standards Australia, Sydney, Australia, 2000. 